\title{
ИНФОРМИРАНОСТ, ОТНОШЕНИЕ И ГОТОВНОСТ НА БЪЛГАРИНА ЗА ИЗПОЛЗВАНЕ НА МЕТОДИТЕ НА ИЗТОЧНАТА МЕДИЦИНА
}

Цв. Търпоманова

\section{LEVEL OF INFORMATION, ATTITUDES TOWARDS AND READINESS TO USE THE METHODS OF EASTERN MEDICINE AMONG BULGARIAN PEOPLE}

Tsv. Tarpomanova

Рез юме. Поддържането на собственото здраве представлява ичеленасочена активност на индивида за превеничя или лечение на заболяванията. В този процес важна роля имат както подходите на традиционната Западна медицина, така и неконвенционалните методи, присъщи на Източната медииина. Целта на настоящото проучване е да изследва информираността, отношението към методите на Източната медицина и готовността на българина за потребяването им. Анкетирани са 250 български граждани, живеещи на територията на гр. Варна, подбрани на случаен принцип. Като запознати със същиността на Източната медицина се самоопределят 44\%, а 71,6\% признават, че им е необходима повече информация за заболяванията, при които тя намира приложение. Около две трети от респондентите (75,6\%) нямат информация за места в град Варна, където се прилагат неконвенционални методи. Почти толкова (70,8\%) не знаят, че към Медицински университет - Варна има работещ Център за източна медицина. Лицата, които се доверяват на неконвенционалните методи като допълнение към основната терапия, са много по-склонни да приложат тези методи отново или да ги препоръчат на близките си. Информираните за Университетския център по източна медииина са убедени в ползата от прилагането на тези методи за предпазване от заболяване. За да се спечели доверието на българина и да се мобилизира личната отговорност за здравето, би било иелесъобразно основните проводници на информация за ролята на методите на Източната медицина да бъдат както медицинките специалисти, така и всички институции, работещи в сферата на общественото здраве.

Su m m ary. The personal health care is an individual purposeful activity for disease prevention and treatment. In this process, important roles play the approaches of the Western medicine as well as the non-conventional methods of the Eastern medicine. The aim of the current study is to assess the level of information, the attitude towards the methods of the Eastern medicine and the Bulgarian people' readiness to use them. The sample consists of 250 Bulgarian citizens selected on a random basis, who live on the territory of Varna city. 44\% of them self-determine themselves as acquainted with the essence of the Eastern medicine but 71,6\% admit that they need more information about the diseases in which treatment these methods may be used. About three-quarters of the respondents $(75,6 \%)$ do not have information about places in Varna where these non-conventional methods are applied. Almost the same number (70,8\%) do now know that there is a working Center for Eastern Medicine at the Varna Medical University. The participants who would trust the use of non-conventional methods as an adjunct to the main therapy are more inclined to use these methods again or to recommend them to their relatives. Those, who are informed about the existence of the Medical University Center for Eastern Medicine are convinced about the advantage of the application of such methods for disease prevention. In order, to win the trust of the Bulgarian people and to mobilize their personal responsibility for health protection, it is necessary to use as main information channels about the role of the Eastern medicine methods the medical specialists as well as all the institutions that work in the public health field.

Key words: Eastern medicine, non-conventional methods, level of information, attitudes, Eastern medicine methods consumers

\section{Въведение}

Поддържането на собственото здраве представлява целенасочена активност на индивида за превенция или лечение на заболяванията, подпомогната от експерти и професионалисти. Нагласата към здравето зависи от характеровите особености, възпитанието и обучението за утвърждаване на здравословен начин на живот, отношението към възможностите на медицината и др. Патерналистичният модел ,лекар/болен“ и характерната народопсихология на българския пациент, от една страна, често е причина за избора на утвърдената Западна медицина, базирана на доказателства. От друга страна, нарастването на дела на социалнозначимите и на хроничните заболявания изисква готовност на националната здравна система за осигуряване както на конвенционални, така и на неконвенционални методи за подобряване здравето на пациентите. [2]

Методите на Източната медицина са се утвърдили вследствие на хилядолетен опит, преди възникването на медицината, почиваща на доказателства, а след това се развиват и прилагат паралелно с нея. [6] Въпреки че съществуват научни биофизични данни за механизма на действие на някои неконвенционални методи, Източната медицина не се изучава в университетите у нас и обикновено се свързва с народните традиции или е привнесена от други страни. [7, 8, 9] За резервираността на пациентите към нея от съществено значение е правното регулиране, т.е. кои методи са разрешени за използване в България и при какви условия. [10] Регламентираните в Закона за здравето и в Наредба №7/01.03.2005 г. неконвенционални методи не влизат в пакета от здравни дейности, осигурен от НЗОК. $[1,3]$ Съвкупността от изброените факти вероятно намалява доверието на хората в ефективността на нетрадиционните методи и ограничава потреблението им.

Настоящото проучване е провокирано, от една страна, от редица материали, публикувани от специалистите от Университетския център по източна медицина, а от друга - от характерните за българина липса на превантивна грижа за здравето и недоверие към неконвенционалните, непризнати от западната конвенционална медицина методи.

Целта на проучването е да изследва информираността, отношението към методите на Източната медицина и готовността на българина за потребяването им.

\section{Материали и методи}

Извършено е анкетно проучване на пълнолетни български граждани, живущи на територията на град Варна, подбрани на случаен принцип. Приложена е собствено съз- 
дадена анкета, разработена съвместно с Университетския център по източна медицина на МУ-Варна, с насочени въпроси към трите целеви аспекта. Изследването е проведено през месец ноември 2018 г. Данните са обработени статистически чрез SPSS v. 24 .и са представени в графичен вид.

\section{Резултати и обсъжАане}

Анкетирани са 250 пълнолетни лица, живущи на територията на град Варна. Разпределението по пол е, както следва: мъже $-25.8 \%$, жени - 73.2\%. Средната възраст на анкетираните е 33.6 г. (SD - 13.85 г.)

Като запознати със същността на Източната медицина се самоопределят 44\%, отрицателен отговор са дали малко повече от половината $(55.2 \%)$ и не са отговорили $0.8 \%$. Болшинството от респондентите $(88.8 \%)$ не са запознати със законовата уредба на неконвенционалните методи. Едва $11.2 \%$ твърдят, че имат информация за правното регулиране на тези методи в България.

Независимо от това, че близо половината от анкетираните лица твърдят, че са запознати с основните характеристики на Източната медицина, 71.6\% признават, че им е необходима повече информация за заболяванията, при които тя намира приложение. Само 6\% смятат, че са достатъчно информирани по темата, а приблизително всеки пети $(22.4 \%)$ не може да прецени дали има нужда от по-задълбочени знания.

Разпределението на източниците на информация за същността и приложението на методите на неконвенционалната медицина е следното: от медии се информират $11.6 \%$, от лекар $-8.4 \%$, от интернет $-40 \%$, от други (познати, приятели) $-19.6 \%$, не са отговорили $0.4 \%$. Не е изненада, че основната част от хората разчитат на информацията от интернет, но е видна и необходимостта от допълнителна работа с медицинските специалисти, на които се разчита да бъдат достатъчно и адекватно информирани по всички въпроси, засягащи здравето.

Липсата на достатъчна информация проличава и от отговорите на конкретно зададения въпрос за заболяванията, при които неконвенционалните методи се прилагат като допълнителна терапия. По-голямата част от анкетираните $(62.8 \%)$ не са дали никакъв отговор, а останалите $37.2 \%$ посочват на първо място заболявания на опорно-двигателния апарат, на второ място - нервно-психични заболявания и на трето - други, като травми, алергии, ендокринни, простудни заболявания.

Около две трети от респондентите (75.6\%) нямат информация за места в град Варна, където се прилагат неконвенционални методи. Почти толкова $(70.8 \%)$ не знаят, че към Медицински университет - Варна има работещ Център за източна медицина.

Здравеопазването днес е насочено предимно към борба с вече възникналото заболяване. В съвременният свят е необходимо да се отделя повече внимание на превенцията на здравето. Пример за това е профилактиката на хипокинезията, която се явява съществен рисков фактор за възникването на редица социално значими болести. Източните оздравителни системи включват физически, дихателни упражнения, методи за концентрация на вниманието, които в своята съвкупност са доказано ефективни за поддържане на добро здравословно състояние. [4] Обнадеждаващ е фактът, че $68.8 \%$ от анкетираните смятат, че методите на Източната медицина предпазват от заболявания.

Същественото предимство на неконвенционалните методи, използвани в холистичния подход за лекуване, е почти пълната липса на странични ефекти. [2, 12] Неконвенционалните методи могат да бъдат включени в цялостното лечение на болестта според $92.4 \%$ от анкетираните. Интересно e, че $13.6 \%$ смятат, че методите могат да се използват при всички заболявания, а според $16 \%$ те биха помогнали само при по-леки състояния. Едва $6.8 \%$ не виждат мястото на Източната медицина като допълнителна терапия.

Анкетираните лица не са подбрани сред пациенти на болничната или извънболничната помощ, а на случаен принцип, затова очакван резултат е, че на $57.2 \%$ не се е налагало да използват методите на Източната медицина, респективно - нямат опит с тях. (Фигура 1)

\section{Фигура 1. Опит с методите на източната медицина}

\section{Използвали ли сте методите на Източната медицина?}

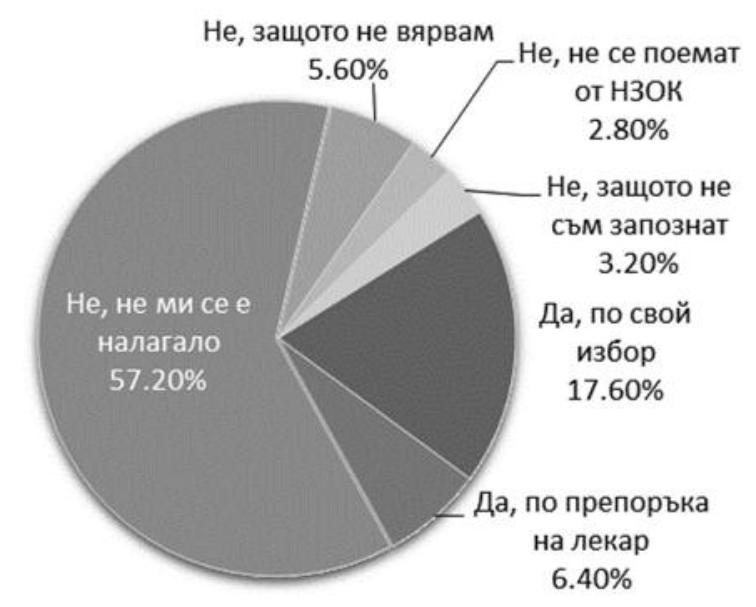

По свой избор към неконвенционалните методи са се обърнали $17.6 \%$ от анкетираните. Интересен е ниският дял на тези, които са използвали методите, защото са им били препоръчани от лекар/медицинско лице - само $6.4 \%$. Като се има предвид значително по - високият процент информирани именно от медицински специалисти, може да се направи извод, че дори и след информацията, лекарите не насочват директно пациентите си към места, където се предлагат неконвенционалните методи. За отбелязване е също и фактьт, че само $2.8 \%$ не използват методите поради липса на финансиране от НЗОК.

Дори и да имат опит с някои от методите на Източната медицина, болшинството от респондентите не могат да преценят кой от използваните от тях методите е най-ефективен $-82 \%$ не са дали отговор на този въпрос. Останалите $18 \%$ оценяват като ефективни акупунктура, акупресура, хомеопатия и билколечение.

Логично е лицата, които са прилагали неконвенционалните методи и са отчели полза за собственото си здраве, да ги използват отново или да ги препоръчат на членовете на семейството си. Най-висок е процентьт на анкетираните, които биха се доверили само на препоръка/ предписание от лекар $-57.2 \%$. И тук Здравната каса не се явява съществен фактор при готовността за потребление от страна на населението. (Фигура 2)

Що се отнася до това на какви условия трябва да отговаря Центърът по източна медицина, за да бъде посещаван, тук мненията на респондентите са разнородни. Все пак $35.2 \%$ биха се доверили на център, който функционира към институция (университет или лечебно заведение). Това е разбираемо с оглед на факта, че неконвенционалните методи все още не се познават добре и не се ползват с нужното доверие. (Фигура 3)

Преобладаващата част от анкетираните (64.8\%) биха отделили до 100 лв. месечно за услуги, предоставяни от Център по източна медицина, 19.2\% - между 100 и 300 лв., $1.6 \%$ - между 300 и 500 лв. и 1.2\% - над 500 лв. На въпроса не са отговорили $13.2 \%$. 
Фигура 2. Готовност за потребление на методите на Иизточната медиична

Бихте ли използвали методите на Източната медицина?

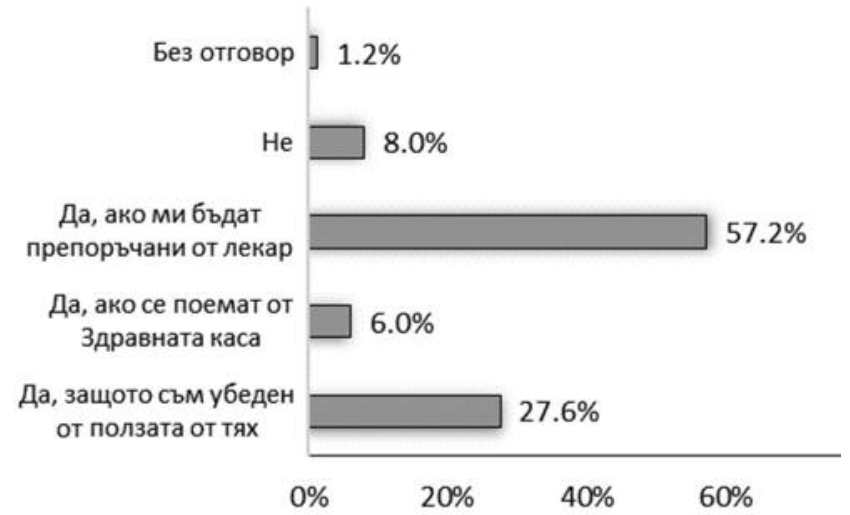

Фигура 3. Изисквания към Центъра по източна медиичина На какви условия трябва да отговаря Центърът по Източна медицина, за да го посещавате?

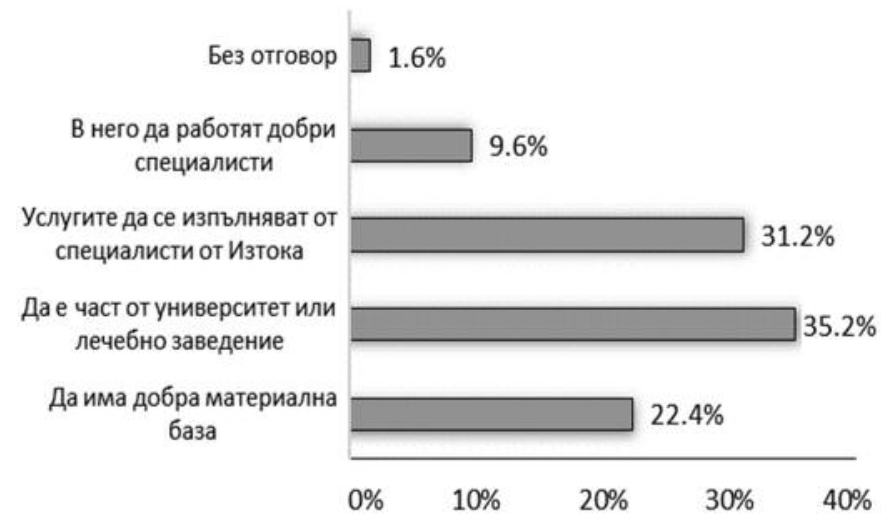

Повече от половината респонденти (56\%) смятат, че в страната ни съществува недоверие към неконвенционалните методи. Отрицателно на този въпрос са отговорили само $4.4 \%$, а голяма част (38.8\%) не могат да дадат оценка до каква степен българите са недоверчиви към прилагането на методи извън препоръчваните от традиционната медицина.

Интересно е, че болшинството анкетирани $(80 \%)$ не могат да преценят дали съществуват подходящи условия за прилагане на методите на Източната медицина в България. Останалите $20 \%$ се разпределят почти равномерно, като изтъкват причини както в полза на положителната си преценка, така и в полза на отрицателната. (Фигура 4)

Статистически значими, но малки като стойност положителни корелации се отчитат между информираността за същността на Източната медицина, и познаването на заболяванията, при които тези методи се прилагат $(\mathrm{r}=0.210$, $\mathrm{p}<0.001 ; \mathrm{r}=0.235, \mathrm{p}<0.0001)$.

Статистически значима средна по сила положителна връзка се открива между информираността и убеждението на анкетираните, че методите на Източната медицина играят превантивна роля $(\mathrm{r}=0.362, \mathrm{p}<0.0001)$, слаба положителна корелация се отчита между самооценката за информираност и мястото на неконвенционалните методи в комплексната терапия на болестите $(\mathrm{r}=0.213, \mathrm{p}<0.001)$

Връзката между основните източници на информация, личния опит и преценката на ефективността и нагласите за използване на неконвенционалните методи не е значима $(\mathrm{r}=-0.048, \mathrm{p}<0.446 ; \mathrm{r}=0.070, \mathrm{p}<0.269$ и $\mathrm{r}=-0.001, \mathrm{p}<0.992)$. Все
Фигура 4. Условия за прилагане на източната медицина в България

Има ли подходящи условия за Източна медицина в България?

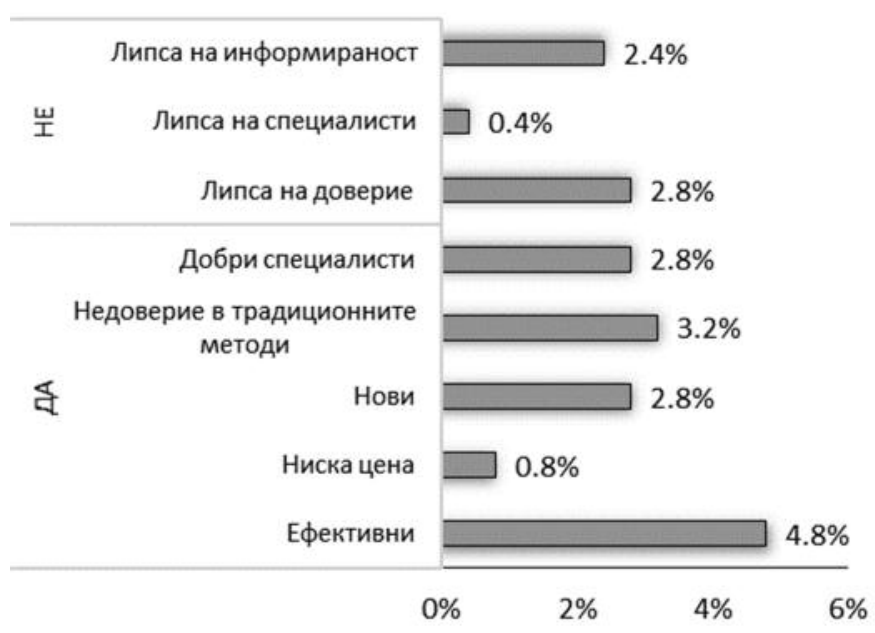

пак, с оглед на преобладаващия процент отговори, че препоръката от медицинско лице би била мотив за използване на методите на Източната медицина, може да се предположи, че информацията, получена от лекар, ще засили нагласите и готовността за потребление на тези методи.

От изследването става ясно, че близо две трети от анкетираните не занаят, че към Медицинския университет Варна функционира Център по източна медицина. Все пак се установява значима корелация между информираността на респондентите за този Център (а вероятно посещение и ползване на услугите, които се предлагат в него) и оценката им за мястото на неконвенционалните методи в комплексната терапия на болестите $(\mathrm{r}=0.142, \mathrm{p}<0.025)$. Не се отчита съществена връзка между това дали анкетираните знаят за съществуването на Университетския център и бюджета, който са готови да отделят $(\mathrm{r}=0.001, \mathrm{p}<0.986)$, условията, на които трябва да отговаря Центъра $(\mathrm{r}=0.033, \mathrm{p}<0.607)$, доверието $(\mathrm{r}=0.042, \mathrm{p}<0.512)$ и нагласите за използване на методите на Източната медицина $(\mathrm{r}=0.020, \mathrm{p}<0.753)$.

\section{Заключение}

Нарастващата потребност от холистичен подход към индивидуалното здраве дава основание да се твърди, че бъдещето принадлежи на Третата медицина, обединяваща съвременната Западна и традиционната Източна медицина. Става ясно, че Източната медицина се оказва много по-подготвена като система от знания, тьй като разглежда болестта като дисбаланс, като загуба на енергия и равновесие в организма. [5, 11]

Без съмнение в България все още има недоверие към неконвенционалните методи на лечение. Почти никой не е запознат с действащата нормативна уредба, повечето се доверяват на информацията от Интернет, голяма част от анкетираните изобщо не са информирани къде във Варна се прилагат подобни методи. Повдига се въпросът за забраната за рекламиране на неконвенционалните методи в български условия, което в немалка степен допринася за липсата на информираност за функциониращите центрове, в частност - за Центъра по източна медицина към МУ - Варна.

От друга страна, лицата, които се доверяват на методите на Източната медицина като допълнение към основната терапия, са много по-склонни да приложат тези методи отново или да ги препоръчат на близките си. Информираните за Университетския център по източна медицина са убедени в ползата от неконвенционалните методи за предпазване от 
заболяване. Все пак, една голяма част биха се доверили на Източната медицина само след насочване от медицинско лице. За да се улеснят общопрактикуващите лекари, които поддържат най-тесен контакт с пациентите, от МУ - Варна биха могли да се организират и проведат специализирани курсове за запознаване със същността и методите на Източната медицина.

Изводите от проведеното проучване са, че е необходима целенасочена работа с медицинските специалисти като авторитетни проводници на информацията за ползите от неконвенционалните методи, но вероятно по този начин ще се оптимизира използването на тези методи при вече възникнало заболяване. Превантивната роля на Източната медицина следва да стане достояние и на здравите лица. Би било целесъобразно тази информация да залегне в програмите за здравна промоция, осъществявани от всички институции, работещи в сферата на общественото здраве.

\section{Библиография}

1. Закон за здравето, в сила от 01.01 .2005 , посл. доп. ДВ. бр.77 от 18.09.2018 г.

2. Манчева, П., Шивачев Я., Неконвенционалните методи на лечение като част от холистичния подход в мениджмънта на хроничната инвалидизираща болест, Здравна икономика и мениджмънт, 2017 г., брой $2(64), 33-35$
3. Наредба №7/01.03.2005 г. за изискванията към дейността на лицата, които упражняват неконвенционални методи за благоприятно въздействие върху индивидуалното здраве (обн. ДВ, бр. 22 от 2005 г.)

4. Николова, Д., Иванова, Е., Манчева, П., Източните оздравителни системи - терапевтични аспекти и тяхното приложение за формиране на здравословен начин на живот, Варненски медицински форум, т. 6 2017, прил. 2, 242-245

5. Руйчев, Б., Болков синдром, В: http://bnr.bg/radiobulgaria/post/ 100233034/doveryava-li-se-bylgarinyt-na-alternativnata-medicina, 2012

6. Янева-Балабанска, И. Неконвенционални методи за диагностика и лечение в България, София, 2007

7. Ignatov, I., Antonov, A., Galabova, T.,Medical Biophysics - Biophysical Fields of Man, Gea Libris, Sofia, 1998

8. Ignatov, I., Energy Biomedicine, Origin of Living Matter, "Informationability" of Water, Biophysical Fields, ICH, Munich, 2007

9. Ignatov, I., Mosin, O.V., Perspective for the Use of Shungite in Water Treatment, Communal Complex of Russia, Vol. 113, No. 11, pp.1-5, 2013

10. Mancheva, P., Is cooperation between Eastern and Western medicine possible in Bulgaria?, Scripta Scientifica Salutis Publicae, vol. 4, 2018, pp. 69-73

11. Shivachev Y, Grozdeva D, Mancheva P, Bogomilova St, Nenova G, Kostadinova T. Multidisciplinary cooperation between complementary and con - ventional medicine with patient suffering from myofascial pain syndrome. Journal of IMAB. 2018;24(3):2125-2128.

12. What Is Holistic Medicine?, Acupuncture and Massage College, Miami, FL, Available from https://www.amcollege.edu/blog/what-is-holistic-medicine, April 19, 2017

\section{Автор}

Цветелина Търпоманова - Учебен сектор „Инспектор по обществено здраве“, МК на Медицинския университет - Варна

Богинята на паметта Мнемосюна заема централно място в древногръцката философска мисъл. В древна Гърция се развива обширна митология на паметта, великолепно реконструирана от Жан Пиер Вернан.

Ако въпросът за паметта е силно застъпен в митичните разкази, то е от една страна, за да бъде подчертана стойността й в една цивилизация на устната традиция (такава е гръцката цивилизация поне до 18 век), а от друга, защото опира до две от главните психологични категории - времето и Аза. В текстовете откриваме четири основни мисловни течения, свързани с темата за паметта.

Първото от тях е представена най-вече от Омир и Хезиод, а така също и от спартанския поет Алкман. В митичните разкази (Илиада, Одисея, Теогония, Дела и дни), творчеството на поета, предвождан от Мнемосюна, съпруга на Зевс и майка на музите, е насочено почти изцяло към миналото, към изначалното време.

...Второто мисловно течение е представено от серия документи от различно естество и от различно време. Тук Мнемосюна се променя: тя вече не е тази, която възпява arche, първичното минало, извора, началото, а по-скоро силата, от която зависи съдбата на душите след смъртта, сила, свързана с последователните превъплъщения на индивида. Така функцията й вече не е космологична, а есхатологична, тай като тя вече не разкрива тайните на праначалата, а начина да бъде достигнат края на времената и да бъде спрян цикъла на поколенията. На прага на Хадес, мъртвият, отпил от водите на Лета, забравя за миналия живот и започва нов живот, съпътстван от изпитания и нещастия, продължаващи вечно като съдбата на Сизиф, Окън или данаидите. За сметка на това душата, която утоли жаждата си в Мнемосюна, си спомня от самото начало всички свои предишни животи и се избавя от тъжния цикъл на мъчителни съществувания, от цикъла на безпаметни повторения.

... Третото мисловно течение е представено най-вече от платонизма. В платоновата теория за анамнезията паметта също е инструмент за освобождаване от времето, който обаче не търси ключа от вратата към изначалието или към края на времената. С Платон паметта се превръща в инструмент на познанието, като усилието за извикване на спомена се отъждествява със самото търсене на истината.

... Тези три течения представят архаичните форми на паметта, които не откриваме при Аристотел - автор на четвъртото течение. При Стагирит паметта вече не е в състояние да освободи човек от времето, а само му осигурява спомените и темпоралните усещания. Сведена от интелектуалната до чувствената част на душата, тя не отваря пътя към безсмъртието, не дава достъп до истината и битието, не е пътя към същинското познание. Нахлуването на усещането в паметта е съпроводено с осъзнаването на тялото, което ни ограничава и се превръща в знак за нашата непълноценност. Дори когато усещанията ни са истинни (Епикур), въображението или просто мненията играят ролята на посредник преди събитията да бъдат складирани в паметта. Съхранените усещания могат да съдържат отклонения от оригиналните, така че спомнянето им не гарантира достъпа до съвършенството. Така аристотелианското течение се явява предвестник на модерните схващания за паметта, „куцукаща и осакатена от своите навици“ (свети Августин).

Жоел Кандо, „Антропология на паметта”, изд. къща „Одри”, 2001 